\title{
Variation of the Pole Length in Pole-Oriented Bonded Rings due to the Location and Number of Injection Points
}

\author{
Katharina H. Kurth and Dietmar Drummer \\ Institute of Polymer Technology, Friedrich-Alexander-Universität Erlangen-Nürnberg, Am Weichselgarten 9, 91058 Erlangen, Germany \\ Correspondence should be addressed to Katharina H. Kurth; kurth@lkt.uni-erlangen.de
}

Received 10 November 2016; Revised 12 January 2017; Accepted 17 January 2017; Published 15 February 2017

Academic Editor: Zhong-Ming Li

Copyright (c) 2017 Katharina H. Kurth and Dietmar Drummer. This is an open access article distributed under the Creative Commons Attribution License, which permits unrestricted use, distribution, and reproduction in any medium, provided the original work is properly cited.

\begin{abstract}
Polymer bonded magnets are compounds consisting of a polymer matrix with embedded hard magnetic filler particles. These materials are mainly used in applications in actor or sensor technology. One example is the application as multipolar encoder wheel in magnetic sensors. Depending on the application different requirements have to be fulfilled, such as a high pole length accuracy and repeatability. This investigation deals with the production of multipolar rings in the injection molding process for sensor applications and influences of the design of the gating system on the pole length accuracy. It is shown that the number of injection points and developing weld lines, as well as the positioning of the injection points, has a major influence on the magnetization characteristics of the molded rings. In general, a positioning of injection points and weld lines in the pole pitch and higher number of injection points lead to rings with a high reproduction accuracy of the pole length of the mold.
\end{abstract}

\section{Introduction}

Magnetic sensor system applications are further increasing, in particular in the automotive industry, but also in mechanical engineering and consumer electronics [1]. Reasons for the increasing use are the enhanced resistance to dirt, vibrations, short impacts, and moisture in combination with the possibility of an efficient production compared to optical systems $[1,2]$. Examples are sensors for the position of the headlight or torque and rotation angle sensors for electronic steering systems [1]. These magnetic sensor systems are always consisting of a magnetic sensitive electric component and a field generating magnet $[1,3]$. As magnetic sensitive electric component mainly hall sensor or magnetoresistive sensors are used [1-4]. Using rotating systems with a multipolar encoder wheel, the electric component senses the alternating magnetic field and, thus, information about the rotational speed, angle, or turning position $[2,5,6]$. In the named examples, the field generating magnet predominantly consists of a polymer bonded magnet with thermoplastic [3,7] or elastomeric matrix [8], which can be rings $[8,9]$ or flexible strips with a multipolar structure [10]. Depending on the application, specific requirements for the magnet have to be ensured, such as a steep slope of the flux density in the pole pitch, a small pole length [7], and precise pole length $[7,11]$.

Polymer bonded magnets consist of hard magnetic filler particles embedded in a polymer matrix consisting of a thermoset, thermoplastic, or elastomeric material $[12,13]$. The processing can be conducted in conventional polymer processing technologies (e.g., injection molding or extrusion $[12,14])$. In comparison to conventionally sintered magnets, polymer bonded magnets enable a high diversity of realizable magnetic field configurations, which can be individually designed for the specific application [1]. Further advantages are the freedom of geometry, narrow tolerances, the possibility of integrating parts, such as bushings or shafts, and a costefficient production of parts in high quantities $[1,12,15,16]$.

The high variety of magnetic field configurations can be achieved by the orientation of anisotropic particles during the process, such that arcuate, convergent, or divergent distribution of the polarization is realizable [1]. For this, a magnetic field is integrated in the mold, which enables the orientation and magnetization of the particles during the injection molding process $[5,17,18]$. For this, the magnetic field has to be guided inside the mold by using certain mold steels with suited permeability $[19,20]$. A second possibility is the 
magnetization of the parts after the injection molding process $[3,5]$. The properties of polymer bonded magnets mainly depend on the filler particle type, amount, and distribution in the polymer matrix [21] in complex interactions with the magnetic field inside the cavity, the process parameters, and the geometry. Common filler contents are between 50 and $65 \%$ [21], common filler materials can be oxide ceramics (e.g.) strontium ferrite $(\mathrm{SrFeO}))$, or rare earth material (e.g., neodymium iron boron $(\mathrm{NdFeB})$ ) [17]. The magnetic properties of pole-oriented injection molded parts can be predicted using magnetostatic simulation models [20, 22, 23].

Prior research on the production of bipolar and multipolar, rectangular shaped polymer bonded magnets shows the influence of the processing conditions during the injection molding process on the magnetic properties of these parts. The flux density in the cavity and the viscosity of the melt are the main influences on the degree of particle orientation [2325]. The magnetic properties of bipolar plates are influenced by the gating system and part thickness and, thus, the melt flow during the injection molding process [25]. For multipolar magnets, no influence of developing weld lines on the course of the flux density on the parts' surface could be detected [24]. Further, the influence of the process parameters, such as melt or mold temperature on the magnetic properties, was investigated [23-25]. For multipolar rings the influences of different processing parameters, different filler content, and different gating systems on the major quality criteria for encoder wheels, such as maximum flux density as well as pole length, are analyzed [26-28]. In particular, the melt and mold temperature lead to an improvement of the pole length accuracy, due to the lower viscosity or lower cooling rate at the surface area and resulting improvement of the orientation of the filler particles [27]. Furthermore, the pole length accuracy is highly influenced by the used gating system, in particular the number of injection points [28]. It was shown that a general deviation of smaller pole length in the pole with centrally located injection point and wider pole length in the pole with centrally located weld line can be detected [28]. Generally, higher melt and mold temperature lead to a lower pole length deviation [27]. However, the influence of the location of the injection point and weld line is not analyzed yet. Further, the cause of the developing effects has to be further evaluated.

This paper deals with the influence of the location and number of the injection points and developing weld lines and, thus, the melt flow behavior on the pole length of multipolar bonded magnets. Further, the influence of the melt flow behavior is analyzed by evaluating short shots, as well as the magnetizing structure in the complete part by using magnetooptic analysis.

\section{Materials and Methods}

2.1. Materials. The materials used for this investigation are a polyamide 12 (Vestamid BS1636, Evonik Industries AG) and a $\mathrm{SrFeO}$ (OP-71, Dowa Holdings Co., Ltd.). Figure 1 shows the $\mathrm{SrFeO}$ particles using scanning electron microscopy. The materials are mixed using a twin screw extruder (Leistritz ZSE HP27, Leistritz Extrusionstechnik $\mathrm{GmbH}$ ) with a nozzle

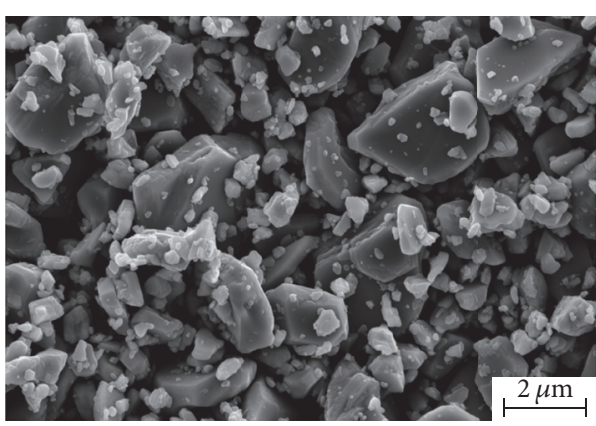

FIGURE 1: Strontium ferrite particles using scanning electron microscopy (SEM).
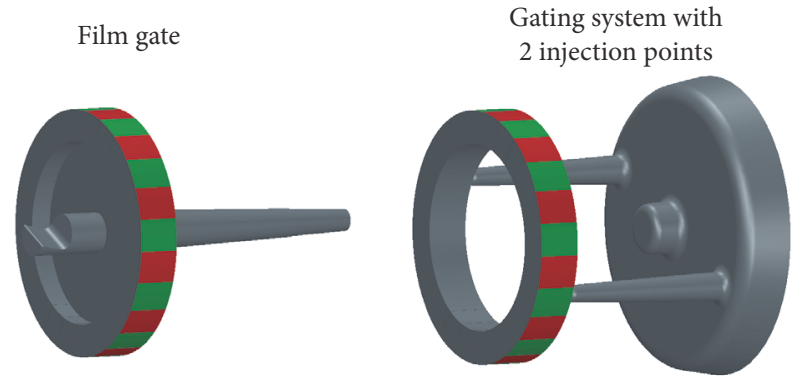

FIGURE 2: Film gate system and pin-point gating system with two injection points.

temperature of $220^{\circ} \mathrm{C}$ and a filler volume content of $50 \%$. Subsequently, the compound is granulated for further processing.

2.2. Specimen. For this research, multipolar magnetic rings with a pole length of $4 \mathrm{~mm}$ and different gating systems are investigated. A defined magnetic field is integrated in the mold (mold dimensions: outer diameter: $30.6 \mathrm{~mm}$, thickness: $4 \mathrm{~mm}$, and height: $5 \mathrm{~mm}$ ) by arranging 24 permanent magnets around the outer cavity surface. Thus, the embedded hard magnetic particles are oriented and partially magnetized during the injection molding process. For the further evaluation, the poles are numbered from 1 to 24 with the same location of each pole number in the mold. Thus, influences of the mold design, such as differences in the magnetic field inside the cavity, can be eliminated.

The evaluated gating systems include a film gate and gating systems with different numbers of injection points located laterally at the side surface (Figure 2). The used gating systems have two, four, eight, and twelve injection points. The location of the injection points and of the developing weld lines can be varied, such that all injection points and weld lines are exactly positioned in the pole center or in the pole pitch. One exception is the gating system with 8 injection points, as the weld line is positioned in the pole pitch while the injection points are located in the pole center; the same applies inversely. Figure 3 depictures the location of the injection points in relation to the pole numbers.

2.3. Processing. For injection molding of the multipolar rings, an injection molding machine of the company Sumitomo 


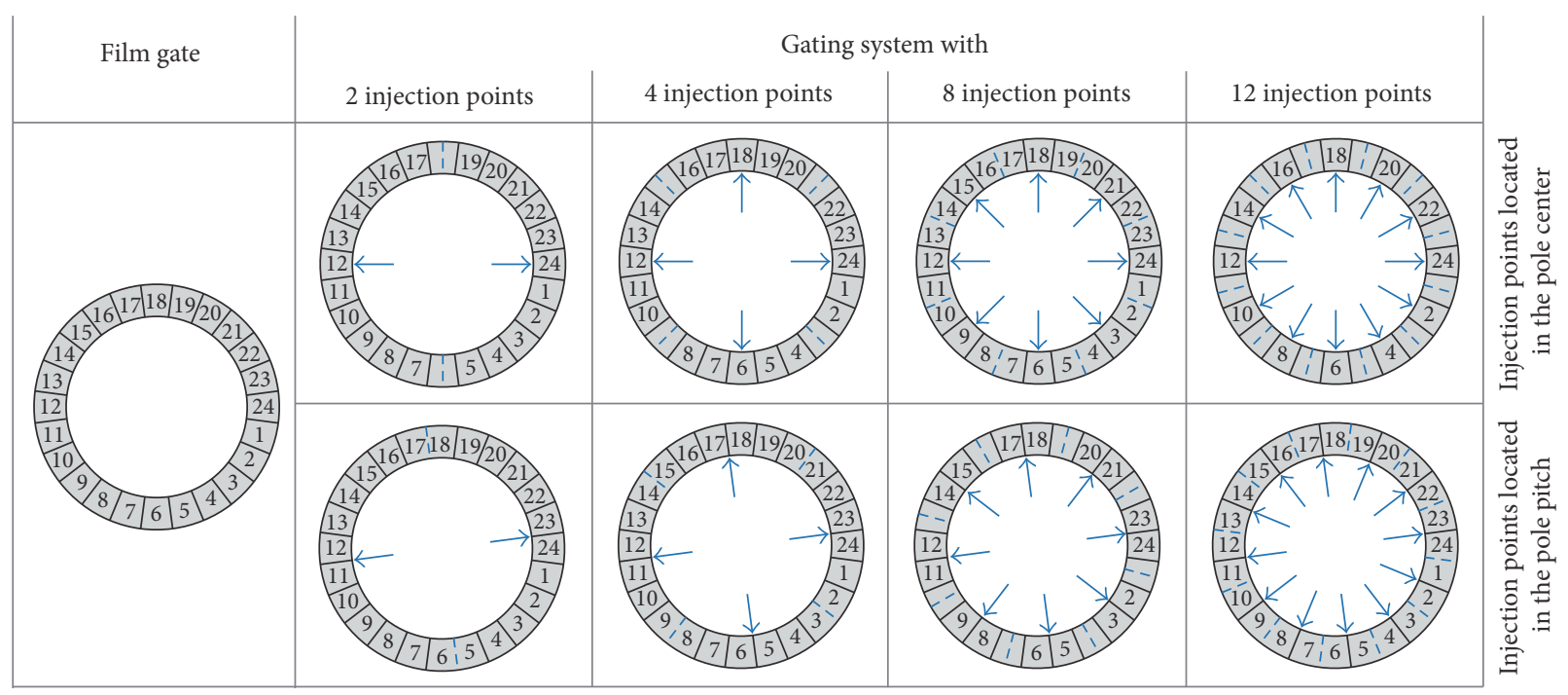

$\longrightarrow$ Injection point

- - - Weld line

FIGURE 3: Location of the injection points in relation to the pole numbers.

Short shots of different gating systems with different number of injection points

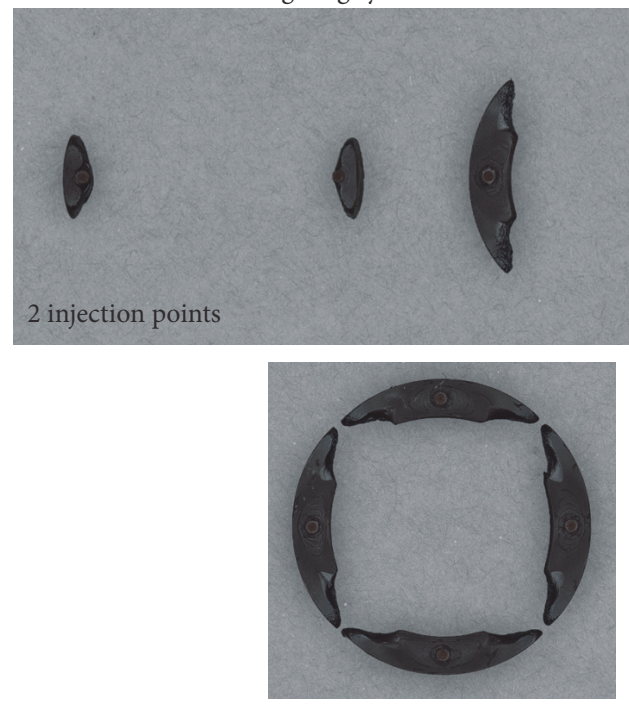

4 injection points

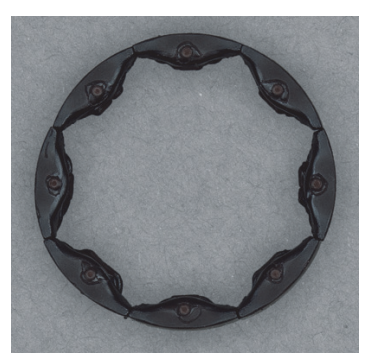

8 injection points
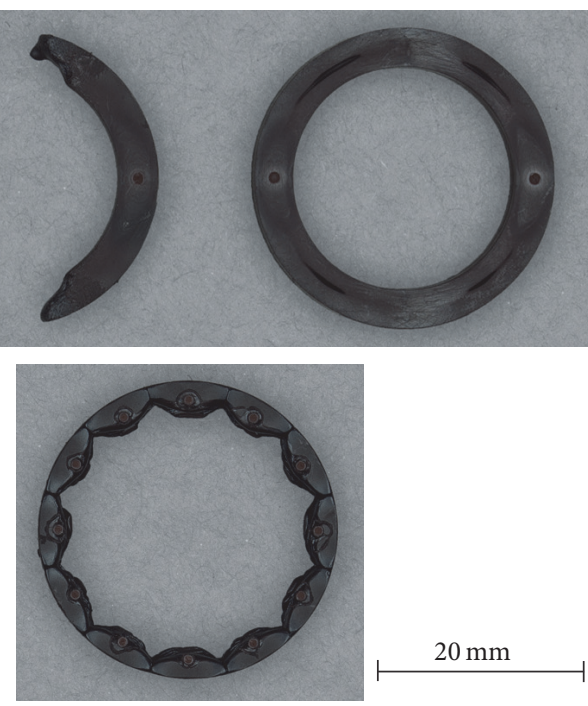

12 injection points

FIGURE 4: Short shots of the multipolar rings with different pin-point gating systems; material: PA12 + 50 vol\% $\mathrm{SrFeO}$.

(SHI) Demag Plastics Machinery GmbH (Demag 25/280-80) with a screw diameter of $18 \mathrm{~mm}$ is used. All rings are produced using the same processing parameters. This includes a melt temperature of $280^{\circ} \mathrm{C}$, a mold temperature of $80^{\circ} \mathrm{C}$, and a holding pressure of 350 bar. The injection speed is varied for the different pin-point gating systems, such that the melt flow rate inside the ring remains constant. Thus, the injection speed for the gating system with two injection points is $40 \mathrm{~mm} / \mathrm{s}$, with four injection points $80 \mathrm{~mm} / \mathrm{s}$ and for eight injection points $160 \mathrm{~mm} / \mathrm{s}$. As there is no continuous melt front developing for the gating system with 12 injection points, the injection speed is also set to $160 \mathrm{~mm} / \mathrm{s}$ (compare to Figure 4). The injection speed for the film gate is also set to $80 \mathrm{~mm} / \mathrm{s}$. As shown in prior research the injection speed does neither influence the pole length accuracy nor the peak flux density of multipolar rings with film gate [26]. The changeover point is defined for each gating system by conducting short shots, which are exemplarily shown in Figure 4. Furthermore, the influence of the magnetic field on the melt flow behavior, in particular at the melt front, is visible. Although the polymer melt is drawn to the outer ring surface to the sintered magnets included inside the mold, the filler 


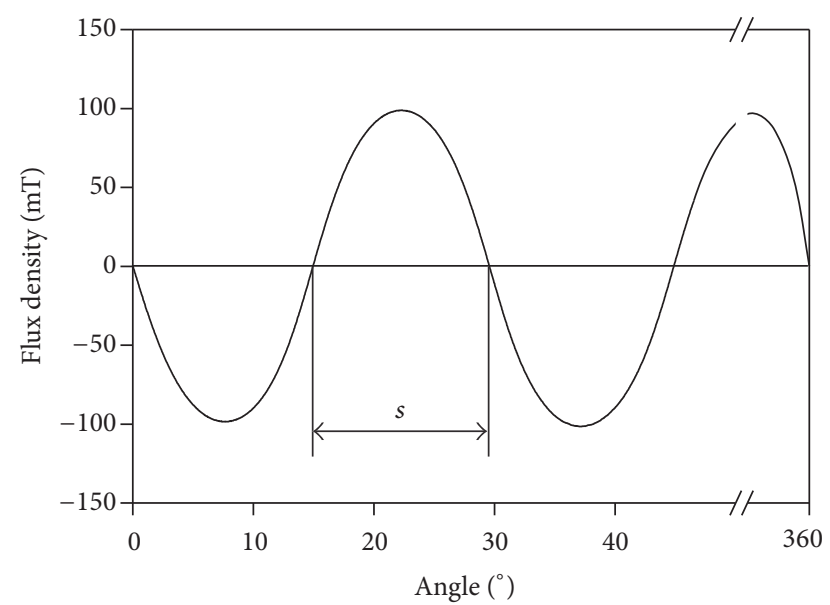

FIGURE 5: Location of the injection points in relation to the pole numbers.

particle distribution remains constant over the whole cross section and at different locations of the flow path [28].

For the gating system with two injection points, short shots with five different changeover points without holding pressure are produced additionally in order to identify the pole length accuracy during the filling phase.

Furthermore, a mold insert with integrated sensors, but without integrated bonded magnets, is used in order to identify the pressure distribution inside the ring. Thus, two pressure sensors (Type 6157B, Kistler Instrumente GmbH, Sindelfingen) and one combined temperature sensor (MTS 408-IR-STS, FOS Messtechnik GmbH, Schacht-Audorf) are integrated in the mold. One sensor of each type is located at one injection point, oppositely from each other. For the gating system with two injection points, the second pressure sensor is located in between the two injection points where the weld line develops; for all other gating systems only the resulting pressure at the injection point location is evaluated. For comparison reasons to other sensor systems, the thermocouple measurement signal will be further evaluated.

2.4. Characterization. The produced rings are evaluated regarding their magnetic properties. For the measurement, a certain characterization device is set up: the rings are fixed to a rotating shaft with attached high-accuracy angular position encoder (RON 786, Dr. Johannes Heidenhain GmbH). The magnetic flux density $B_{R}$ oriented perpendicular to the outer ring surface of the rings is measured using a hall sensor (KSY44, Siemens AG, Munich) and related to the measured angle (Figure 5). The active area of the sensor is positioned in a distance of $0.5 \mathrm{~mm}$ to the rings' outer surface, whereas the sensor is positioned flexibly with sliding contact in order to adjust to inaccuracies of the rings' concentricity. By using a regularly replaced Teflon tape, the abrasion of the sensor surface is prevented.

As encoder wheel one important quality criterion is the pole length $s$, which is defined as the distance of two adjacent zero crossings (Figure 5). Thus, the pole length is interpolated linearly by using the two closest measurement points before and after the zero crossing. The pole lengths are then summarized regarding their characteristic poles, which includes, for example, poles with centrally located injection point or weld line. For the gating system with two injection points characteristic poles are, for example, the poles numbers 12 and 24 with centrally located injection point or 6 and 18 with centrally located weld line (compare to Figure 3 ). As shown in prior research, the pole length of the rings with film gate correlates with the pole length of the mold [26]. In order to identify the process influences, the pole length deviation with regard to the pole length of the mold and, thus, the pole length of the rings with film gate are presented. For the evaluation of the pole length of the short shots only completely filled poles are considered. To guarantee comparability and equal measurement conditions a reference ring is measured in between each set of five rings with the same processing parameters. The deviations of the results of the reference ring have to be in the range of $\pm 0.03^{\circ}$ regarding their pole length. Compared to the measurement of completely filled rings, the fixing of the short shots cannot be conducted by centering on the inner diameter, which results in higher standard deviations during the measurements.

Further, rings with different gating system are prepared in order to analyze the filler particle orientation using a scanning electron microscope (SEM) (Ultra Plus, Carl Zeiss AG, Oberkochen, Germany). For the investigation cross section polishes of rings embedded in a thermoset resin were made. The polished surface, located at the ring's half height, is sputtered with platinum and palladium. Beforehand, the rings have been demagnetized. The particle orientations of the rings with different gating systems are analyzed at the pole with integrated injection point and weld line, as well as in the pole pitch at the outer ring surface structure as well as $800 \mu \mathrm{m}$ from the outer ring surface.

Furthermore, using the magnetooptic analysis method, the magnetization characteristics of the rings are evaluated. For the evaluation the magnetooptic analyzation device "MiniMo" (Matesy GmbH, Jena) with the sensor type B is used. The magnetooptic principle is based on the Faraday effect, which describes the polarization plane of linearly polarized light when passing through a magnetooptical medium. This device can be used for a qualitative examination of hard magnetic material structures. However, due to the noncalibrated visualization, the shown grey values can only be evaluated qualitatively. For the evaluation, grinded sections of one sample of each processing variation in the rings' half height are prepared. The rings are then analyzed at different locations, which include the injection point, weld line, as well as the poles in between these two characteristic locations.

\section{Results and Discussion}

3.1. Pole Length. The pole length is one important quality criterion of multipolar bonded magnetic rings used as encoder wheels. Hereinafter, the results for the pole length of the multipolar rings with different gating systems and for short shots are presented. 


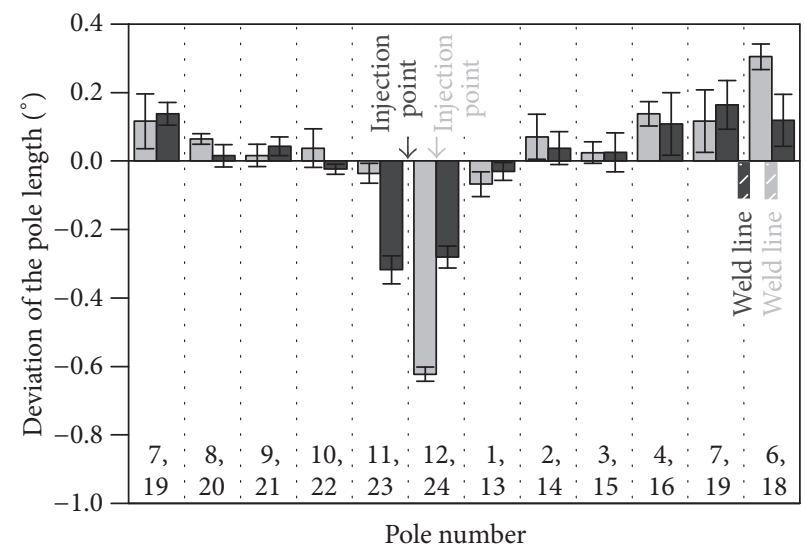

Injection points located

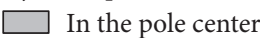

In the pole pitch

(a)

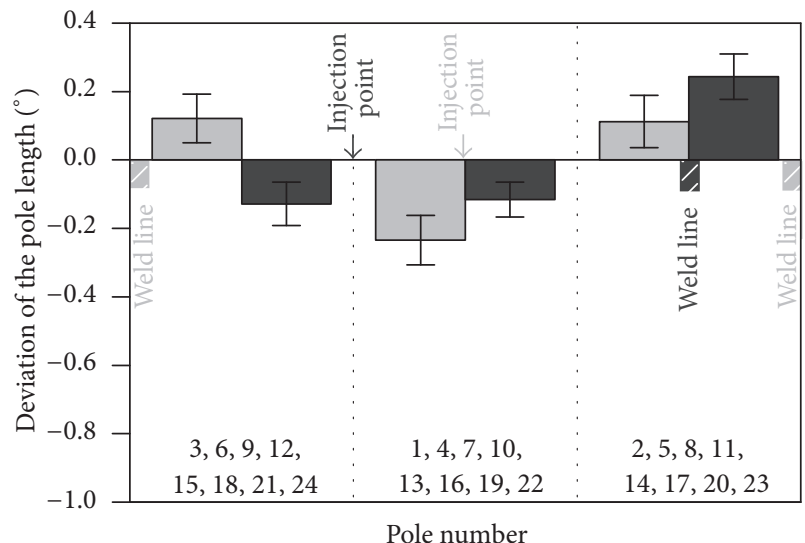

Injection points located

$\square$ In the pole center

In the pole pitch

(c)

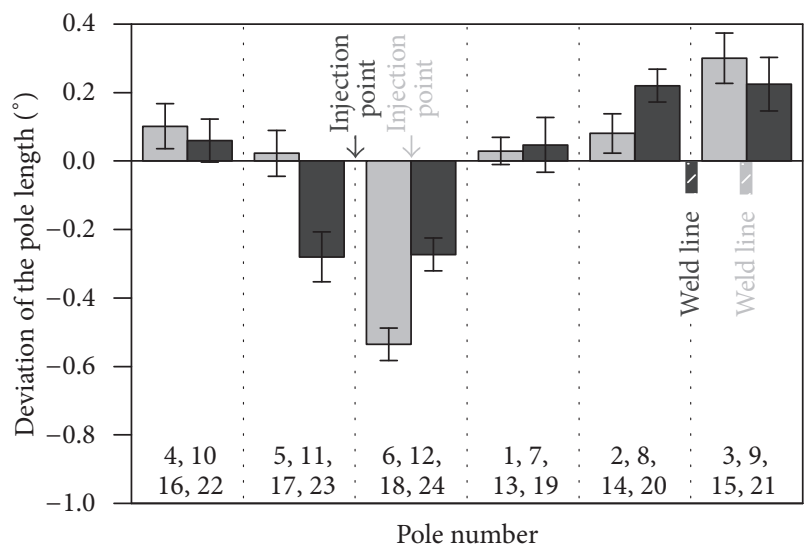

Injection points located

$\square$ In the pole center

In the pole pitch

(b)

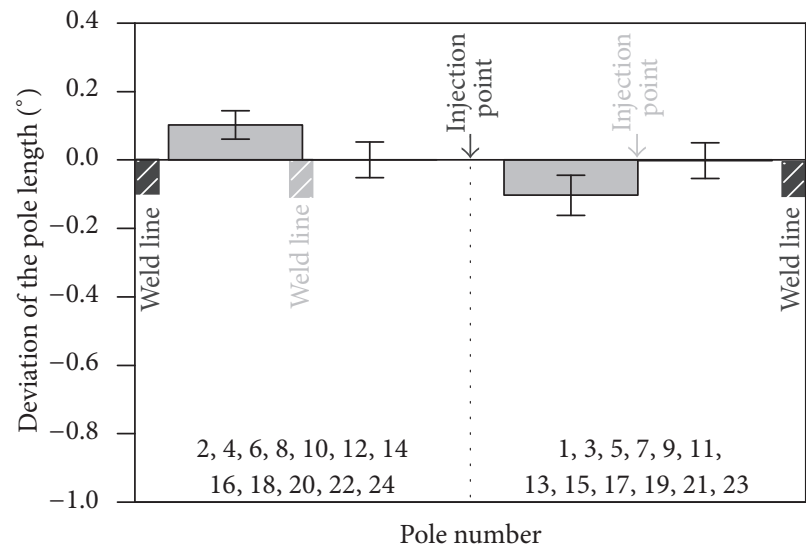

Injection points located

$\square$ In the pole center

In the pole pitch

(d)

Figure 6: Influence of the injection point location on the pole length deviation of the rings with a gating system with twelve injection points in comparison to the rings with film gate.

Figure 6 shows the deviation of the pole length compared to the rings with film gate for different gating systems and locations of the injection points. For all used gating systems the location of the injection points, as well as weld lines, is in the pole center or pole pitch. Figure 6(a) shows the results for the rings with a gating system with two injection points. For the rings with the injection points located in the pole center, the pole length at the injection location is significantly smaller, the pole length at the weld line location significantly broader compared to the reference. Furthermore, the pole length deviation of all other poles is rather broader but not significantly distributed, as it was already shown in [27] for a different filling degree. For the rings with the injection point located in the pole pitch, the same deviation pattern can be recognized. However, the maximum deviation is smaller compared to the rings with the injection point location in the pole center. Further, the two adjacent poles to the injection point and weld line are influenced.

For the gating systems with four, eight, and twelve injection points (Figures 6(b), 6(c), and 6(d)) the same deviation pattern can be recognized. For the rings with the gating system with eight injection points, the weld line is located in the pole pitch while the injection point is in the pole center. Thus, it can be seen that the pole length deviation is broader compared to the reference and the characteristic location influences both adjacent poles. For the ring with the gating system with twelve injection points it can be seen that the alternating positioning of injection point and weld line at each pole pitch leads to an almost identical reproduction of the reference and, thus, the mold.

The pole length deviation of the poles with integrated injection point or weld line is summarized in Figure 7. For 


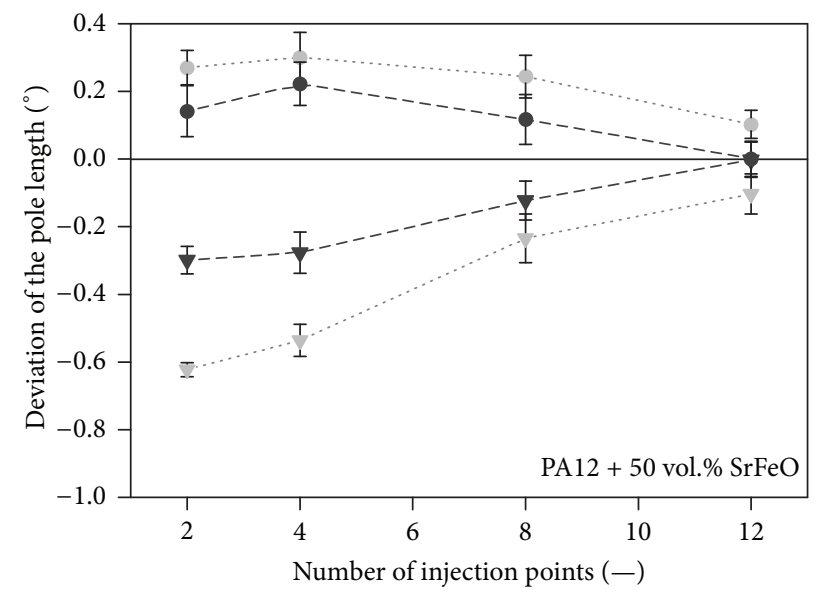

Pole with

$\rightarrow-$ Injection point

- - Weld line

Injection point/weld line is located

.... Centrally in the pole

- - In the pole pitch

FIGURE 7: Influence of the injection point location on the pole length deviation of the rings with a gating system with twelve injection points in comparison to the rings with film gate.

this, the pole length deviation of the pole with centrally located characteristic or the average of the two adjacent poles for the positioning of the characteristic in the pole pitch is used. It can be seen that the maximum deviation of the pole length can be significantly reduced by the positioning of injection points and weld lines in the pole pitch, as well as increasing the number of injection points and thus, reducing the flow distance.

Figure 8 shows the deviation of the pole length of the short shots compared to the pole length of the rings with film gate. The used gating system is a pin-point gating system with two injection points. The described deviation pattern can be seen for the completely filled rings with and without holding pressure. Furthermore, the significant pole length deviation in the pole with centrally located injection point can be seen for all short shots with different changeover points. This shows that the presented effect, the deviation pattern with strongly reduced pole length in the pole with injection point, is already caused during the filling phase.

3.2. Scanning Electron Microscope (SEM). The filler particle orientation has been investigated for different locations of the rings, as well as different number of injection points and their position. The particle orientations for different locations of the rings with two injection points, which are located in the pole center or pole pitch, are shown in Figure 9. The $\mathrm{SrFeO}$ particles are anisotropic with a magnetic preferred direction perpendicular to the large surface of the mainly plateletshaped particles, which leads to a horizontal alignment of the filler particles with a horizontally oriented magnetic field. It can be seen that there is no particle orientation close to the surface layer at all positions along the flow front due to the fast cooling at the cold mold surface. In a distance of $800 \mu \mathrm{m}$ from the ring surface a defined particle orientation can be identified. In the pole center the particles are horizontally; in the pole pitch they are vertically aligned. Optically no differences in the orientation in regard to the flow path lengths and the position of an injection point or weld line can be identified. Furthermore, no differences in between the rings with different gating systems can be optically identified. However, defining the degree of orientation of the particles is not possible due to the irregular particle shape. The filler particle orientation of multipolar bonded rings is discussed in more detail in [28].

3.3. Magnetooptic Analysis. Figures 10 and 11 show the magnetooptic analysis of the multipolar rings with a gating system with two injection points for different characteristic positions at the ring; Figure 12 shows the analysis for a ring with film gate. For all variations, the alternating pole structure can be clearly seen. Furthermore, for the rings with the pin-point gating system, a surface layer with different magnetization structure can be identified, which cannot be identified in the ring with film gate. The pole with centrally located injection point (black) shows a reduced pole length at the surface layer, whereas the two adjacent poles (white) shift towards this pole at the surface layer. The poles in between injection point and developing weld line also show a shifted magnetization at the surface layer, whereas the pole length remains constant in the surface layer. The surface layer of the pole with centrally located weld line is shifted towards the adjacent poles, such that the pole length at the surface layer is increased. For the rings with the injection point and weld line located in the pole pitch (Figure 11) a similar shift of the magnetization at the surface layer can be seen. However, there is no shifting visible at the pole pitch, where the injection point or weld line is located. Furthermore, this qualitative effect can be also seen in the short shots, as well as rings with different number of injection points.

3.4. Pressure and Temperature Courses. The temperature and pressure distribution during the injection molding process inside the cavity for two different gating systems are exemplarily shown in Figure 13. The temperature profile during injection molding indicates the entering of the melt in the ring cavity. The low peak temperature of approximately $130^{\circ} \mathrm{C}$ for all gating systems can be explained by a combination of the measurement of the surface temperature, the fast cooling of the melt due to the high degree of filling, and the relatively long responding time of the sensor itself. Thus, the peak temperature will not be further evaluated.

The increase in pressure starts after the increase in temperature and, thus, after the polymer enters the ring cavity. As the time difference in between the increase in temperate and the increase in pressure varies for the different gating systems, it can be concluded that the filling of the rings is conducted without pressure inside the ring, whereas the holding pressure leads to a pressure of almost the set pressure level. For the gating system with two injection points, the pressure distribution close to the injection point and weld line is very similar regarding height and course. For this reason, the 


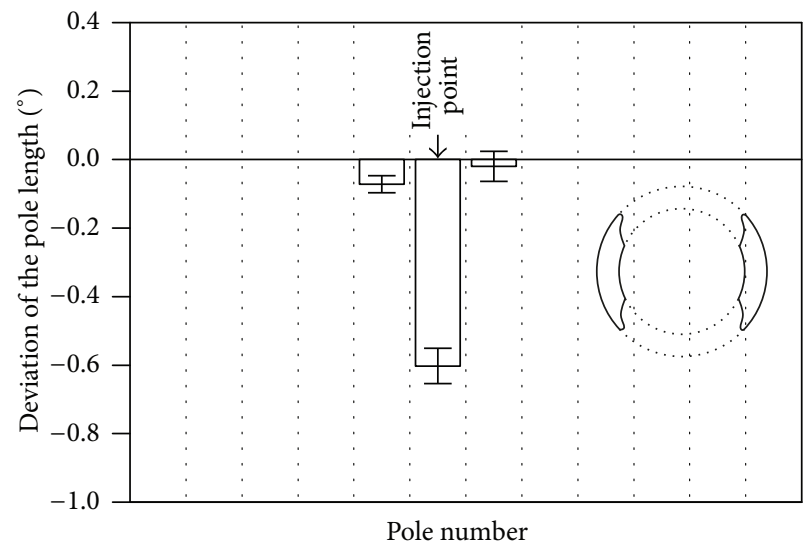

(a)

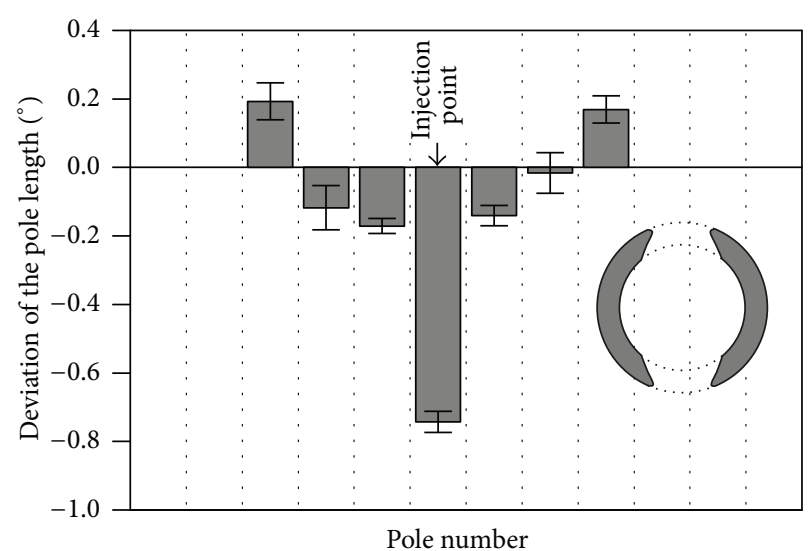

(c)

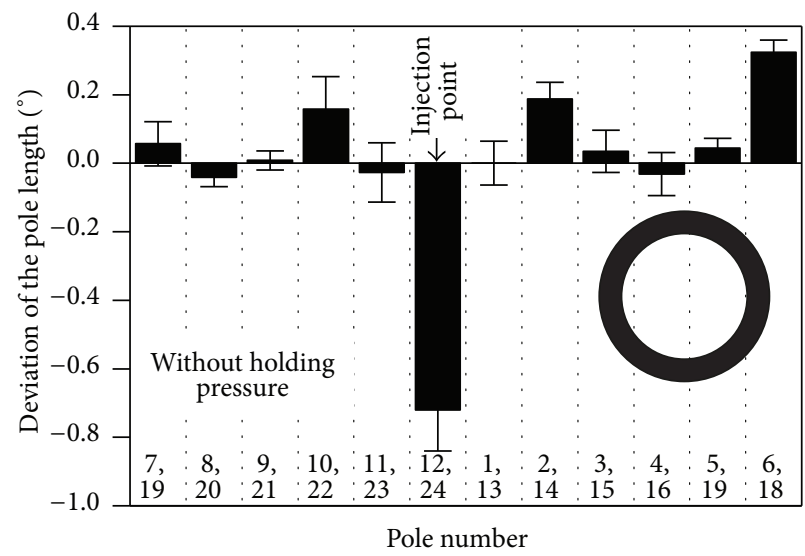

(e)

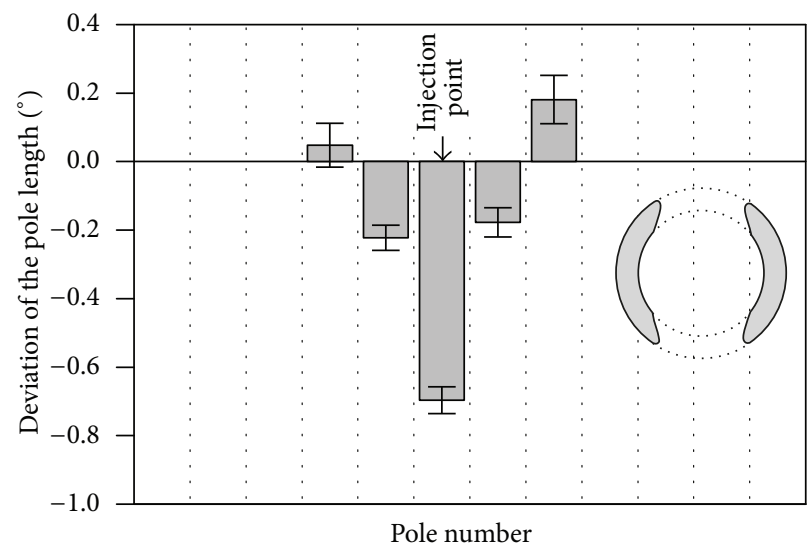

(b)

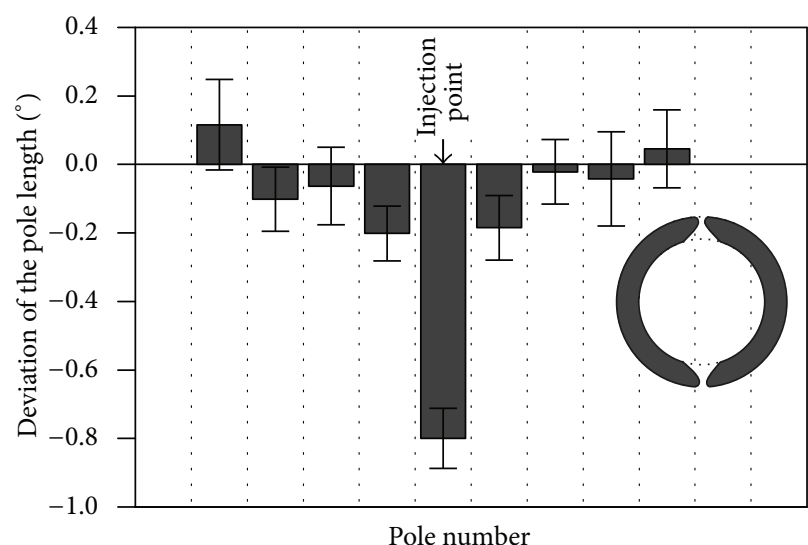

(d)

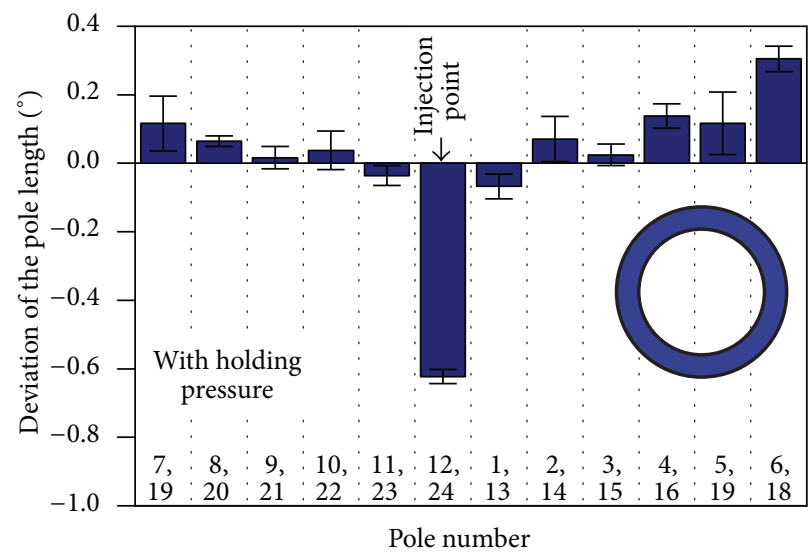

(f)

FIGURE 8: Deviation of the pole length for short shots with a gating system with two injection points, each located in the pole center, in comparison to the rings with film gate.

pressure distribution for the different gating systems was only evaluated for the location close to the injection point.

3.5. Discussion. The results of the magnetic properties show a certain pattern for the deviation of the pole length for different number of injection points, as well as their location. It is shown that the pole length is significantly reduced in the pole with injection point and increased in the pole with weld line. This deviation is quantitatively reduced by locating the injection point and weld line in the pole pitch, as the deviation is split into the two adjacent poles. Furthermore, this deviation pattern is already existent in the short shots. Consequently, it can be concluded that this effect is related to the filling and, thus, melt flow behavior of the compound. Due to the pressureless filling of the ring, pressure related effects on the deviations in the pole length, in particular in the 


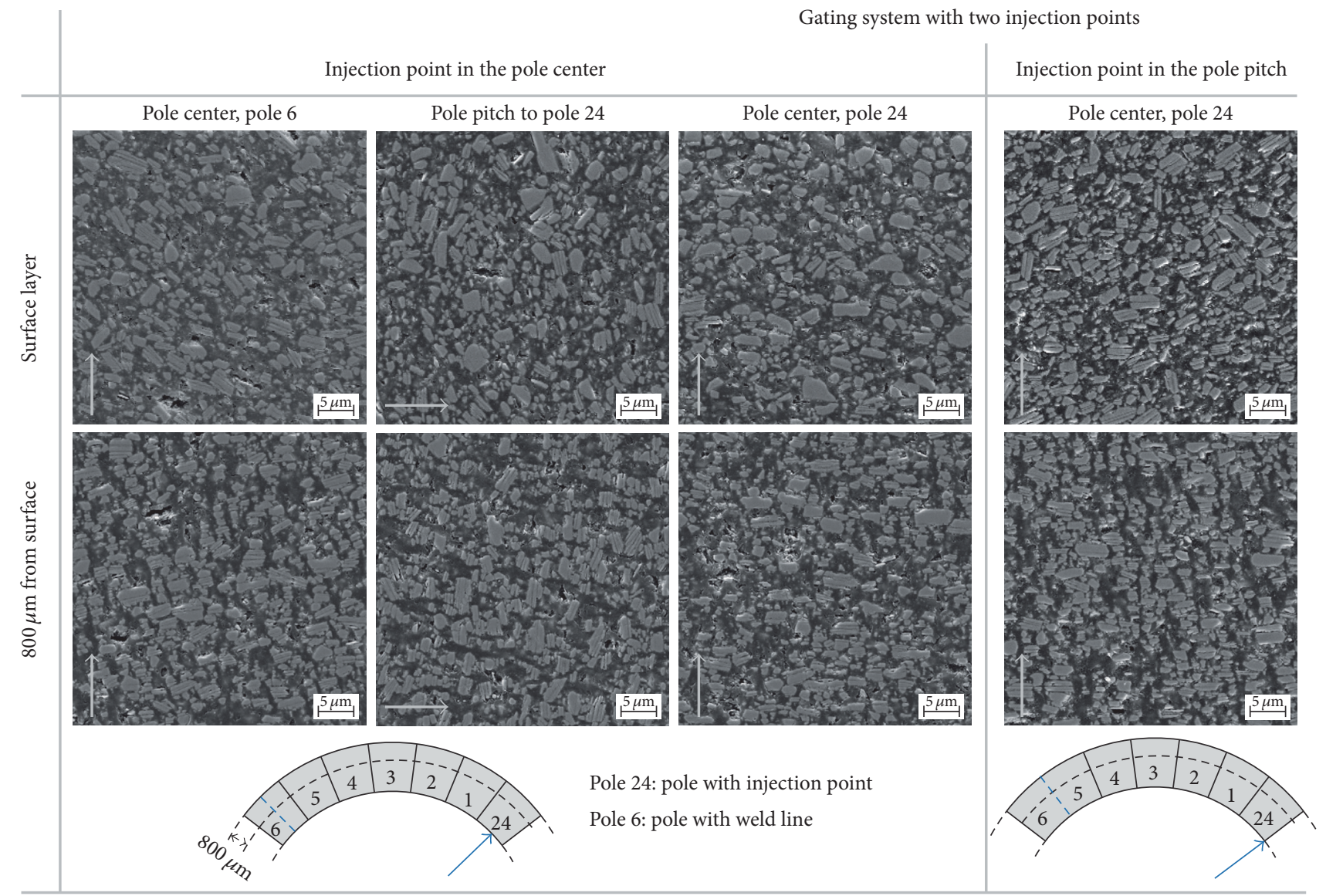

$\longrightarrow$ Direction of the integrated magnetic field

Upper edge of the picture is aligned parallel to the outer ring surface

FIGURE 9: Filler particle orientation for rings with a gating system with two injection points; material: PA12 + 50 vol\% SrFeO.

pole with centrally located injection point, can be excluded. The magnetooptical analysis shows a developing surface layer with a shifted magnetization to the center, which qualitatively fits to the measured results of the pole length deviation. Thus, it is assumed that the developing surface layer leads to the presented pole length deviation. Furthermore, the particle orientation at different locations is presented. A frozen nonoriented layer at the outer ring surface can be identified. In a certain distance to the surface layer, the particle orientation corresponds to the integrated magnetic field inside the mold. Differences in regard to the flow length, number of injection points, and location of the injection points cannot be optically identified. Presumably, the presented effects are caused by the freezing of the melt and, thus, filler orientation in combination with the magnetization of the particles, during the filling phase.

The orientation of nonmagnetic platelet-shaped particles during the injection molding process is mainly shear induced $[21,29]$; the orientation of magnetic particles is mainly caused by the integrated magnetic field, as seen ideally in the scheme in Figure 14. For the magnetic field induced orientation of the filler particles in accordance with the arcuate magnetic field inside the cavity, the viscosity of the matrix material is significant. It is assumed that the particles reorientate according to the magnetic field at each location during melt flow. Furthermore, the filler particles are magnetized by the magnetic field inside the cavity. Due to the cold cavity surface, a surface layer with high viscosity or frozen matrix material and, thus, poor filler particle orientation regarding the magnetic field is developing [28]. The prior magnetization in combination with the flow-induced orientation, which is frozen at the surface layer, leads presumably to the layer with shifted magnetization.

\section{Conclusions and Future Work}

These investigations show that the production of multipolar signal transmitter for magnetic sensors with integrated magnetization during the injection molding process is possible. Further, the design of the gating system and the position of the injection points have a major influence on the pole length accuracy. It can be shown that the magnetization of the surface layer is shifted compared to the inner part due to the melt flow during the filling phase. Furthermore, this surface layer strongly influences the pole length measurements. For this, a smaller pole length in the area of the injection point 


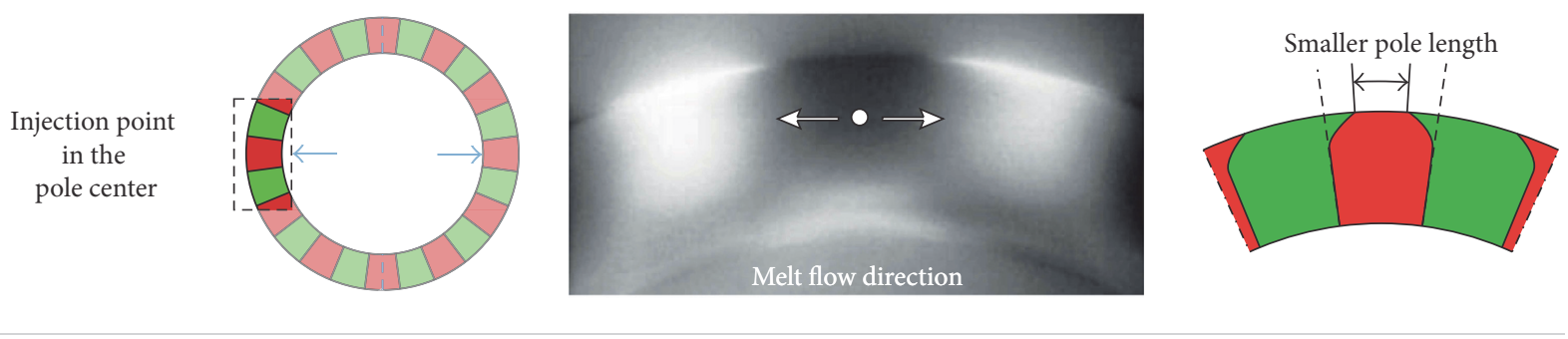

Poles between injection point and weld line
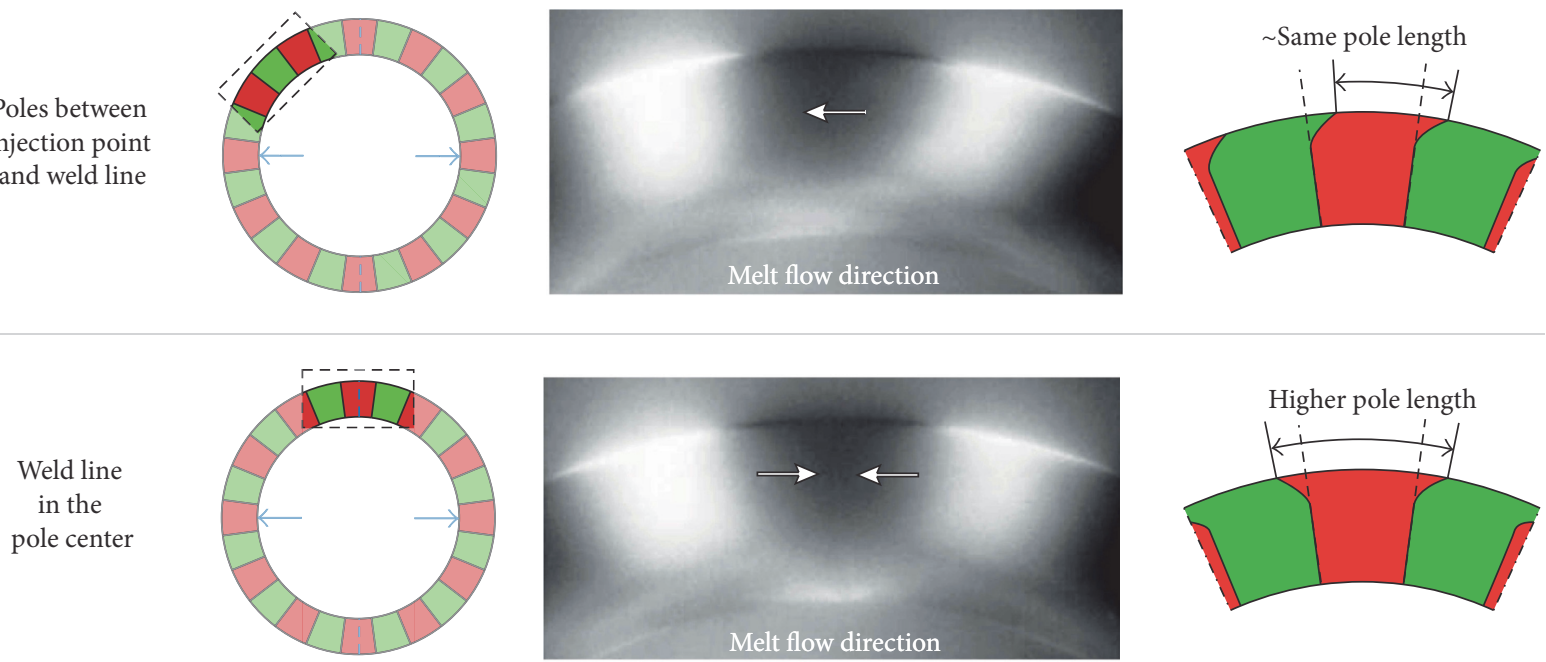

FIGURE 10: Magnetooptic analysis of the ring with a gating system with two injection points, each located in the pole center.
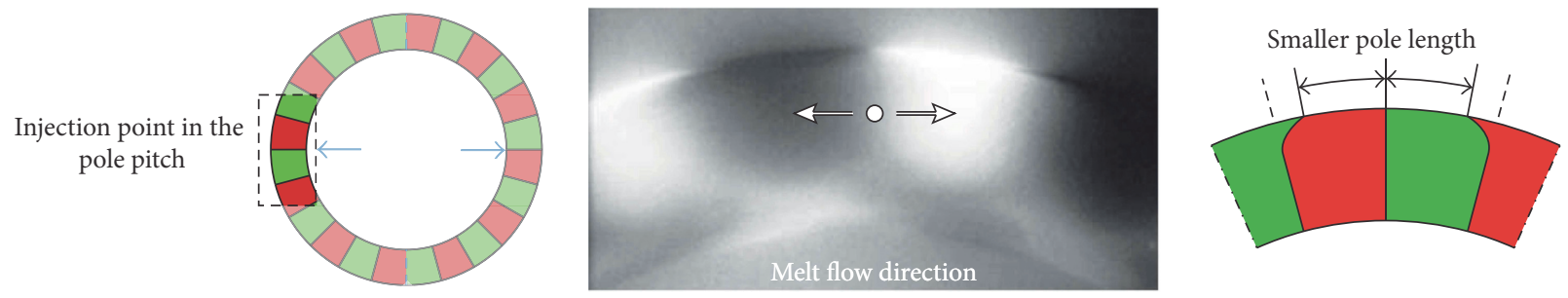

Poles between injection point and weld line
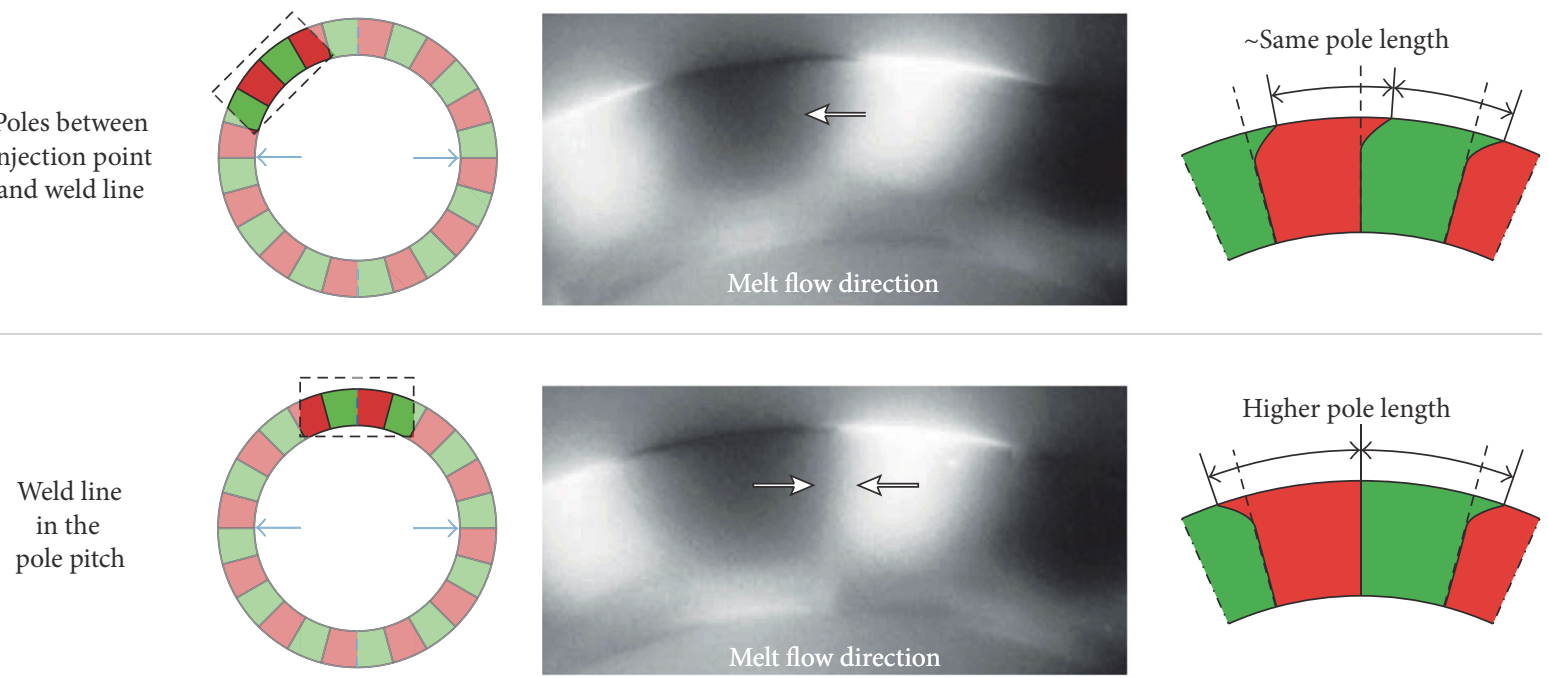

FIGURE 11: Magnetooptic analysis of the ring with a gating system with two injection points, each located in the pole pitch. 

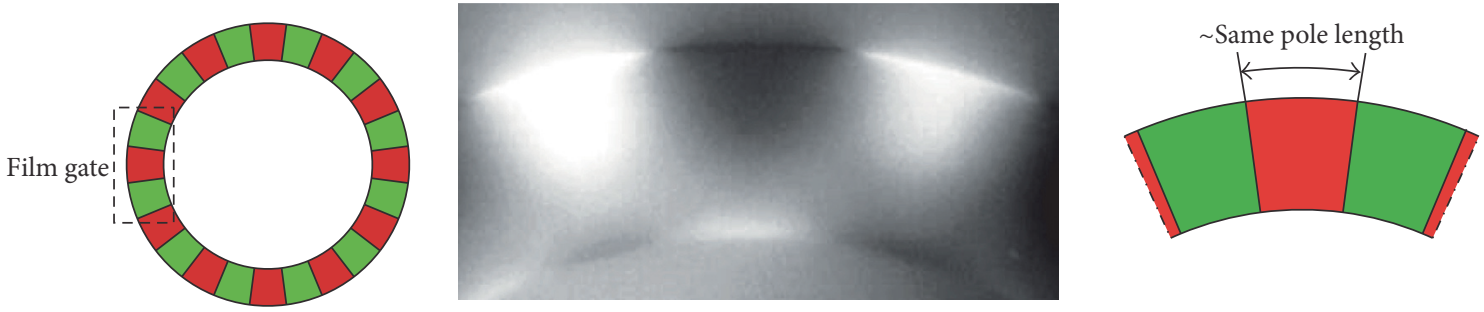

FIGURE 12: Magnetooptic analysis of the ring with a film gate.
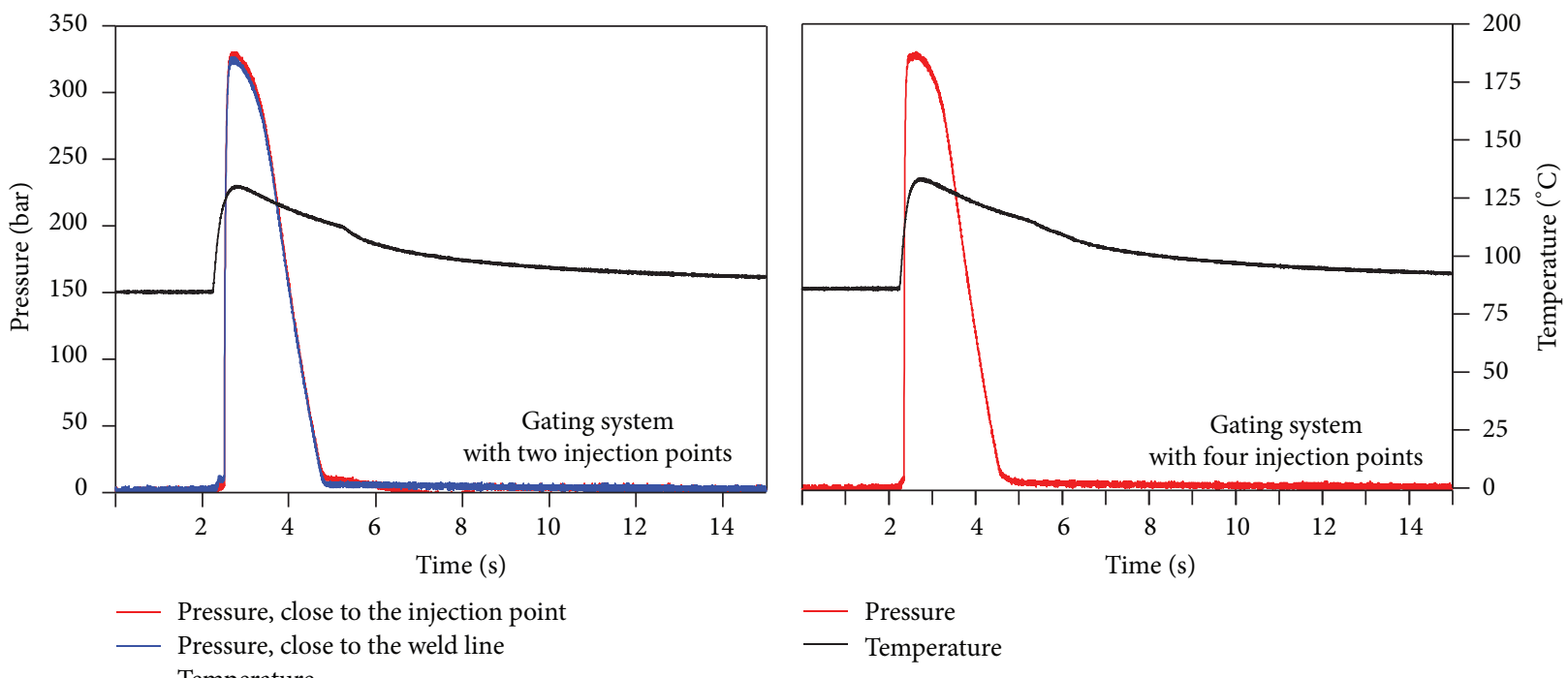

Pressure, close to the injection point
Pressure, close to the weld line
Temperature

Figure 13: Pressure and temperature courses during the injection molding process.

Filler particle orientation due to
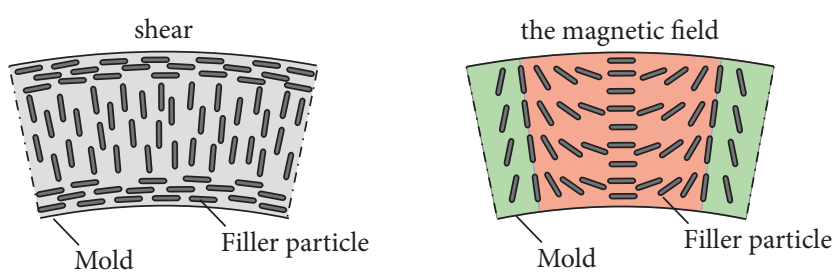

FIGURE 14: Scheme for the comparison of the ideal filler particle orientation only due to shear during mold filling or the magnetic field.

and a broader pole length in the area of the weld line can be identified. The pole length accuracy can be improved by increasing the number of injection points, as well as the positioning of the injection points and weld lines in the pole pitch. For the rings used in this investigation with 24 poles, good results were achieved using a film gate or a 12 pinpoint gating system with the location of the injection points in the pole pitch, such that each pole pitch includes either an injection point or weld line.

In future work, it shall be investigated if the development of the surface layer can be prevented by adapting the process conditions (e.g., cooling of the melt at the cavity surface). Further, it shall be evaluated if the distance of the flux density measurement is determinant for the influence of the developed surface layer. The aim would be the production of rings with a high pole length accuracy and a gating system, which can be cost-efficiently removed after the injection molding process. Furthermore, the influence of different matrix materials, as well as number of poles, on the pole length accuracy shall be investigated.

\section{Competing Interests}

The authors declare that they have no competing interests.

\section{Acknowledgments}

The authors would like to thank the German Research Foundation (DFG) for funding this project (DFG/DR 421/12-1). They also extend their gratitude to Evonik Industries AG for providing the polymer that was used as matrix material.

\section{References}

[1] T. Schliesch, "Magnete mit virtuoser Polverteilung," Sonderdruck Industrieanzeiger, no. 23, pp. 20-21, 2010.

[2] C. P. O. Treutler, "Magnetic sensors for automotive applications," Sensors and Actuators, A: Physical, vol. 91, no. 1-2, pp. 2-6, 2001. 
[3] M. Grönefeld, "Polymergebunde hartmagnetische Werkstoffe," in Magnetwerkstoffe für Technische Anwendungen, Haus der Technik e.V, Essen, Germany, 2014.

[4] B. Hagemann, "Kunststoffgebundene Magnete in der Antriebstechnik-Möglichkeiten und Grenzen," in Kunststoffgebundene Dauermagnete, Springer, Düsseldorf, Germany, 2004.

[5] D. Steingroever, "Kunststoffgebundene, isotrope Magnetwerkstoffe in der Sensorik," in Kunststoffgebundene Dauermagnete, Springer VDI, Düsseldorf, Germany, 2004.

[6] J. R. Brauer, Magnetic Actuators and Sensors, John Wiley \& Sons, Hoboken, NJ, USA, 2014.

[7] A. Schmidbauer, "Anforderungen, Anwendungen und Trends kunststoffgebundener Dauermagnete in der Sensorik," in Kunststoffebundene Dauermagnete, Springer VDI, Düsseldorf, Germany, 2004.

[8] T. Miyagawa, T. Takehara, T. Murakami, and T. Takajo, "A new high-performance plastic magnetic encoder," SAE Technical Paper 2009-01-1293, 2009.

[9] K. Reif, Ed., Sensoren im Kraftfahrzeug, Springer, Wiesbaden, Germany, 2nd edition, 2012.

[10] I. Dexter Magnetic Technologies, Sensor-Grade Magnets for Position Sensing Applications.

[11] S. Gauthier, "Tracking motion with multipole-magnet Hall sensing," Motion System Design, vol. 54, no. 10, pp. 34-37, 2012.

[12] G. Reppel, "Duroplastgepresste Magnete-Werkstoffe, Verfahren und Eigenschaften," in Kunststoffgebundene Dauermagnete, Springer, Düsseldorf, Germany, 2004.

[13] H. Schumacher, "Elastomergebundene Magnetsysteme," in Kunststoffgebundene Dauermagnete, Springer VDI, Düsseldorf, Germany, 2004.

[14] M. Grönefeld, "Review on bonded magnets," in Bonded Magnets: Proceedings of the NATO Advanced Research Workshop on Science and Technology of Bonded Magnets, Newark, U.S.A. 22-25 August 2002, NATO Science Series, pp. 1-12, Springer Netherlands, 2003.

[15] A. Gardocki and D. Drummer, "Improvement of the filler orientability during injection molding of multi-polar SmComagnets by premagnetization," in Proceedings of the 2nd International Electric Drives Production Conference (EDPC '12), Nuremberg, Germany, October 2012.

[16] T. Sakai, K. Nakamura, and A. Morii, "Plastics magnet manufacturing process: mixing, kneading, and injection molding," International Polymer Processing, vol. 6, no. 1, pp. 26-34, 1991.

[17] P. Barlog, S. Gewalt, and T. Wiebel, "Die Anziehungskraft nimmt zu. Polymergebundene Ferritmagnete für die Elektrifizierung im Automobil," Kunststoffe, vol. 105, no. 9, pp. 177-179, 2015.

[18] S. Eimeke, A. Gardocki, S. Amesöder, and E. Schmachtenberg, "Mould design from pole to pole," Kunststoffe International, no. 5, pp. 70-73, 2007.

[19] K. H. Kurth and D. Drummer, "Improvement of the magnetic properties of injection molded polymer bonded magnets," in Proceedings of the 3rd International Electric Drives Production Conference (EDPC '13), Nuremberg, Germany, October 2013.

[20] S. Eimeke and G. W. Ehrenstein, "Injection molding tool design for the production of plastic-bonded magnets using FEMsimulation," in Proceedings of the Rubber \& Plastics Technical Conference, Qingdao, China, 2005.

[21] E. Baur, S. Brinkmann, T. Osswald, N. Rudolph, and E. Schmachtenberg, Saechtling Kunststoff Taschenbuch, vol. 31, Carl Hanser, München, Germany, 2013.
[22] T. Schliesch, B. Hagemann, H. Hartnuss, F. Poehlau, D. Steingroever, and D. Drummer, "Combined bonded rotor for DC motors with different magnetic materials and field areas," IEEE Transactions on Magnetics, vol. 40, no. 4, pp. 2077-2079, 2004.

[23] S. Eimeke, A. Gardocki, Z. Brocka, and E. Schmachtenberg, "Injection molding of polymer-bonded magnets with multipolar structure," in Proceedings of the 66th Annual Technical Conference of the Society of Plastics Engineers, Plastics Encounter at (ANTEC '08), pp. 1504-1508, Milwaukee, Wis, USA, May 2008.

[24] S. Eimeke, Spritzgießen multipolarer, kunststoffgebundener Dauermagnete [Dissertation], Universität Erlangen-Nürnberg, Erlangen, Germany, 2008.

[25] D. Drummer, Verarbeitung und Eigenschaften Kunststoffgebundener Dauermagnete [Dissertation], University of ErlangenNuremberg, Erlangen, Germany, 2004.

[26] K. H. Kurth and D. Drummer, "Influences on the magnetic properties of injection molded multipolar rings," International Polymer Processing, vol. 31, no. 3, pp. 356-363, 2016.

[27] K. H. Kurth, D. Drummer, and E. Grünewald, "Influences of the variation of process parameters on the pole length of multipolar bonded magnets," in Proceedings of the SPE ANTEC, Indianapolis, Ind, USA, May 2016.

[28] K. H. Kurth and D. Drummer, "Effect of the variation of the gating system on the magnetic properties of injection molded pole-oriented rings," Journal of Polymer Engineering, 2016.

[29] C. Heinle, Z. Brocka, G. Hülder, G. W. Ehrenstein, and T. A. Osswald, "Thermal conductivity of polymers filled with nonisometric fillers: a process dependent, anisotropic property," in Proceedings of the 67th Annual Technical Conference of the Society of Plastics Engineers (ANTEC '09), pp. 883-889, Chicago, Ill, USA, June 2009. 

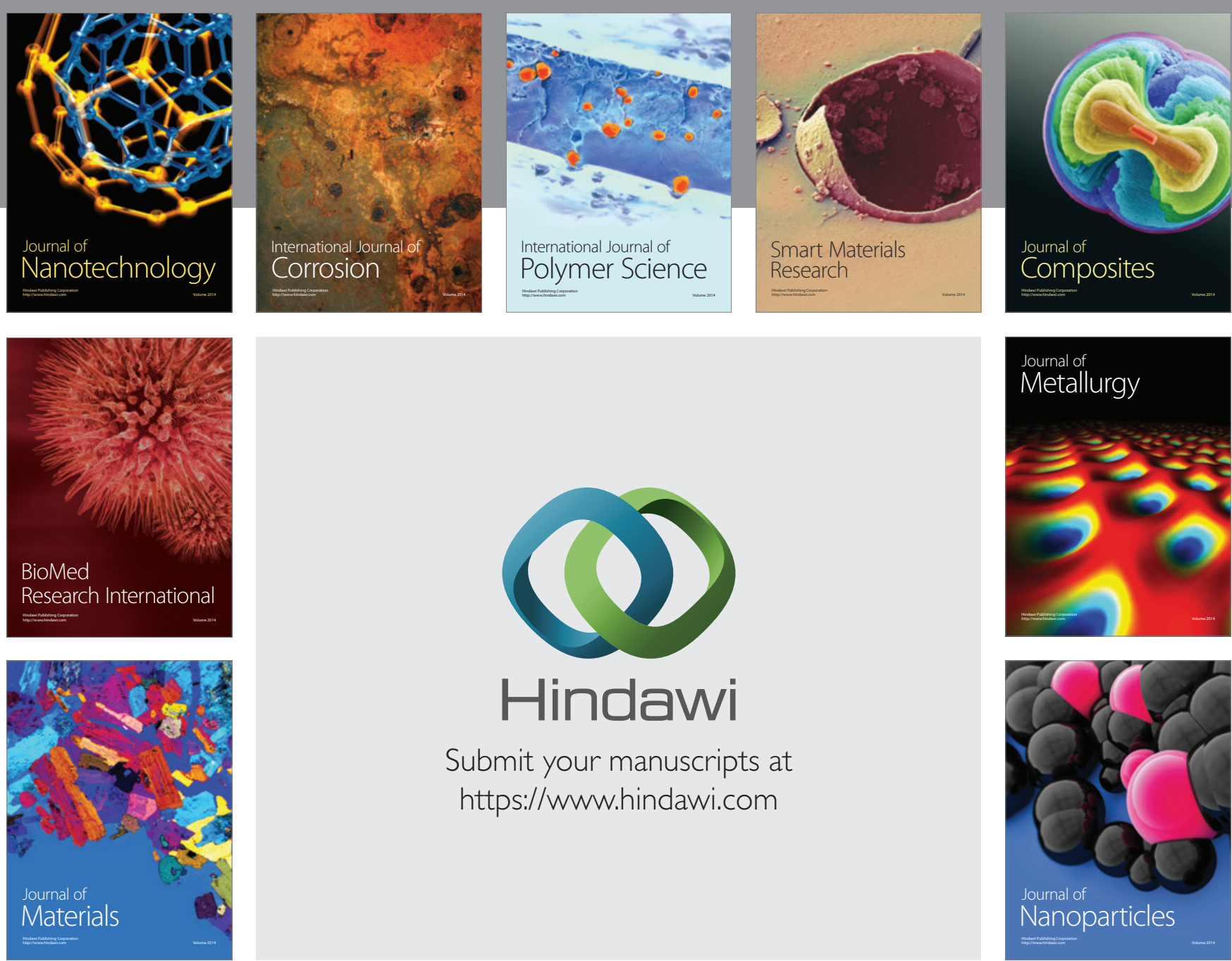

\section{Hindawi}

Submit your manuscripts at

https://www.hindawi.com

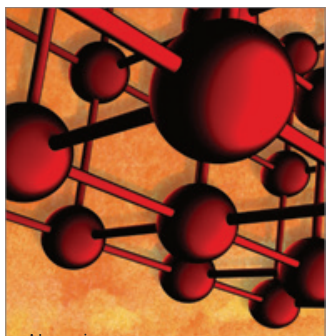

Materials Science and Engineering
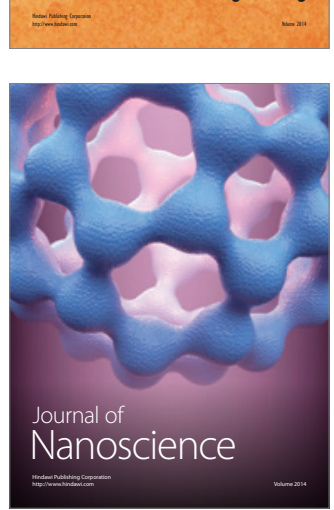
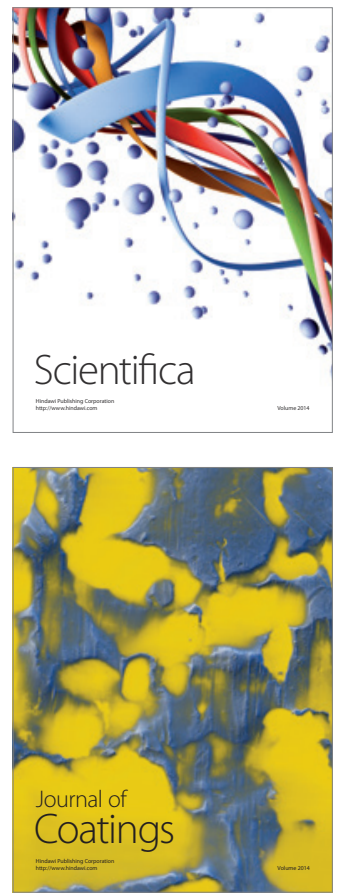
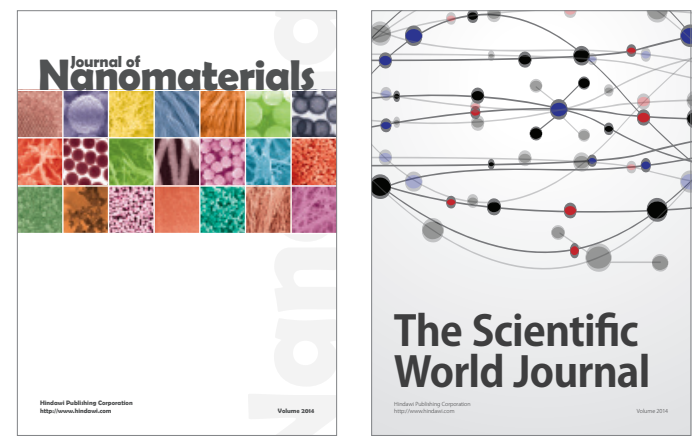

The Scientific World Journal
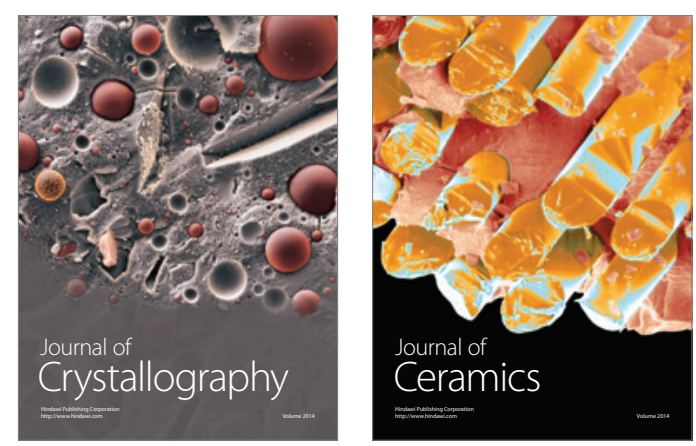
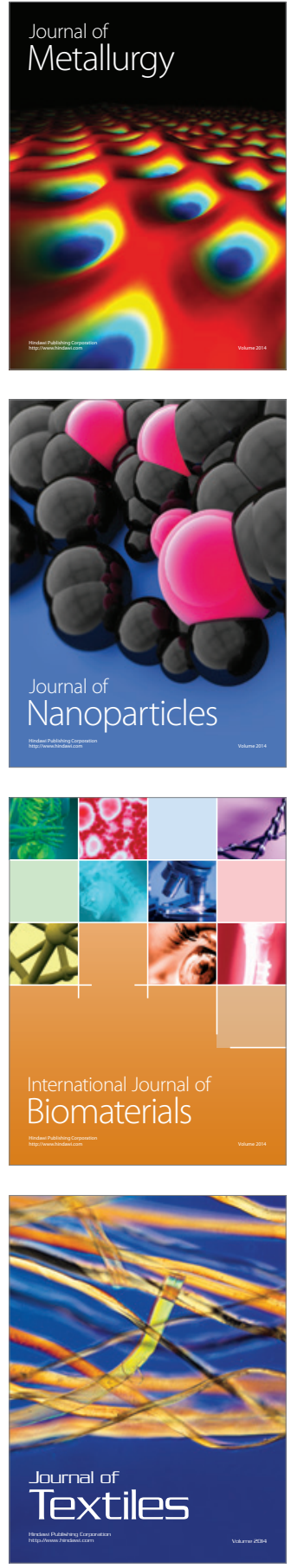